University of Nebraska - Lincoln

DigitalCommons@University of Nebraska - Lincoln

Educational Psychology Papers and

Publications

Educational Psychology, Department of

2009

\title{
Alcohol Expectancies among High School Students in Inner Mongolia, China
}

Duane F. Shell

University of Nebraska-Lincoln, dshell2@unl.edu

Ian Newman

University of Nebraska-Lincoln, inewman1@unl.edu

Ming Qu

Nebraska Health \& Human Services System

Follow this and additional works at: https://digitalcommons.unl.edu/edpsychpapers

Part of the Educational Psychology Commons

Shell, Duane F.; Newman, lan; and Qu, Ming, "Alcohol Expectancies among High School Students in Inner Mongolia, China" (2009). Educational Psychology Papers and Publications. 97.

https://digitalcommons.unl.edu/edpsychpapers/97

This Article is brought to you for free and open access by the Educational Psychology, Department of at DigitalCommons@University of Nebraska - Lincoln. It has been accepted for inclusion in Educational Psychology Papers and Publications by an authorized administrator of DigitalCommons@University of Nebraska - Lincoln. 


\title{
Alcohol Expectancies among High School Students in Inner Mongolia, China
}

\author{
Duane F. Shell, ${ }^{1}$ Ian M. Newman, ${ }^{1}$ and Ming Qu ${ }^{2}$ \\ 1. Nebraska Prevention Center for Alcohol and Drug Abuse, University of Nebraska-Lincoln, Lincoln, NE, USA \\ 2. Nebraska Health \& Human Services System, CODES Project, Lincoln, NE, USA \\ Corresponding author - Duane F. Shell, NPCADA, University of Nebraska-Lincoln, \\ P.O. Box 880345, Lincoln, NE 68588-0345, USA; e-mail dshell2@unl.edu
}

\begin{abstract}
Objective - This study examines differences in Chinese high school students' alcohol expectancies by drinking status (nondrinker, occasional drinker, regular drinker) and gender (male, female).

Method - The authors administered the Chinese Adolescent Alcohol Expectancy Questionnaire (CAEQ) to a convenience sample of 1244 high school students $(M=627 ; F=617)$ from schools in Hohhot City and Tongliao City in Inner Mongolia, China.

Results - Differences were found in the 8 CAEQ factors ( 3 negative and 5 positive factors). Regular drinkers had lower negative consequences and higher positive perception expectancies than nondrinkers or occasional drinkers. Nondrinkers had higher harm to person/reputation expectancies than occasional or regular drinkers. Occasional drinkers had higher beneficial/moderation and lower harm to person/reputation expectancies than nondrinkers. Boys had higher positive perception expectancies than girls.

Conclusion - Expectancies are associated with Chinese adolescents' drinking. Identifying the characteristics of alcohol consuming youth can inform the development of prevention interventions and alcohol policies.
\end{abstract}

Keywords: adolescents, alcohol, China, expectancies, Inner Mongolia

\section{Introduction}

\section{Current Alcohol Situation in China}

Between 1949 and 1981, beer production in China increased 91 times. ${ }^{1}$ The World Health Organization reported this increase in per capita consumption of pure alcohol (liters) among adults 15 years of age and older in China to be the second highest in the world. ${ }^{1}$ Today, China is the world's largest producer of beer ${ }^{2,3}$ and liquor. ${ }^{3}$ (Wine production in 2004 was 370,000 tons, up $15 \%$ from 2003. ${ }^{4}$ ) Using total midyear population and production data, the World Advertising Research Centre (2005) estimated per capita consumption of spirits alone to be 3 liters of pure alcohol, and spirits, beer, and wine combined to be 4.0 liters. ${ }^{3}$ The World Health Organization estimates per capita alcohol consumption for the population 15 years and older at 4.45 liter. ${ }^{5}$ Estimates of home-made alcohol, popular in rural areas, are unknown. 
These changing patterns of alcohol use can be attributed to China's expanding population and to the changes in the economy and society since China opened to the west that have resulted in changes in the way alcohol, especially beer, is produced, marketed, and distributed.

Beginning in the 1990s, foreign alcohol companies initiated numerous joint ventures in China, diversifying the marketplace with the introduction of foreign brands. This newly internationalized business sector has consolidated production, increased production efficiencies, reduced production waste, and developed efficient distribution and sales networks, resulting in economies of scale that have ensured low prices despite the rising costs of raw materials. At the same time, increasingly sophisticated market research has helped companies, especially foreign companies, better target their advertising and sales promotion strategies. China's expanding population alone is a significant assist to increased sales without the need to increase the proportion of drinkers in the population or the amount they drink.

These changes in alcohol availability, coupled with the rapidly expanding availability of private automobiles and the construction of high-speed highways, have no doubt contributed to the increases in traffic crash injuries and death. Since 1983, there has been a rising prevalence of alcohol-related disorders in the medical records of the Chinese health care system. ${ }^{6}$ (pp. 1-33) Similar changes in alcohol-related social problems like crime, violence, and family disorder are reported. ${ }^{6}$ (pp. 1-33)

Despite these changes in alcohol availability and the suggestions of increasing alcohol-related problems, China does not experience the magnitude of alcohol-related problems common in the West. A long history of experience with alcohol control policies, strong familycentered traditions, and a culture emphasizing moderation and self-respect have no doubt helped. Nevertheless, the government has initiated actions to reduce the likelihood of alcohol-related problems. In the last decade, concerns about quality control in the production process have led to increased production regulations. The production of high alcohol liquors is discouraged. The government has increased taxes on spirits, restricted licenses for the spirits industry, and begun to regulate the import of spirits. ${ }^{7}$ The government's aim is for spirits to contain no more than $40 \%$ alcohol. In 2007, the government announced a law prohibiting the sale of alcohol to those younger than 18. At the same time, there has been increasing enforcement of the drunk-driving traffic laws.

As these social changes continue, there will be a continuing need to develop public policies that allow for alcohol's role in society while reducing alcohol-related problems. A better understanding or the psychological and sociological aspect of alcohol use can help the development of public policies. This article describes a technique to better understand alcoholrelated adolescent behaviors and illustrates the value of this approach with data of a type that could be valuable in developing public policies. Contemporary data, however, must always be viewed in an historical context.

\section{Alcohol Use and Chinese Culture}

China has a long history of alcohol production and use. ${ }^{8}$ Archaeologists have recovered alcohol vessels made 6000 to 7000 years ago, suggesting that alcohol use in China originated at least as early as $5000 \mathrm{BCE}$. Cases of alcoholism were recorded in Chinese traditional medicine texts as early as $2200 \mathrm{BCE},{ }^{9}$ and there is historical evidence of government control of alcohol as early as the reign of Emperor $\mathrm{Yu}$ in 2298-2205 BCE. ${ }^{10}$ Occasionally, the fall of a dynasty was attributed to alcohol. ${ }^{11}$ Nevertheless, alcohol use is considered an integral part of Chinese culture and often accompanies music, dance, and other literary and artistic activities. ${ }^{12} \mathrm{Jiu}$ (alcohol in Chinese) is regarded as the representation of happiness and the embodiment of auspiciousness, but jiu is also one of the Four Vices, or "disasters": wom- 
anizing, gambling, drinking, and smoking. ${ }^{13}$ Alcohol is a staple at weddings, banquets, celebrations, family association meetings, ceremonies, and other auspicious occasions. The Chinese especially enjoy alcohol at their traditional festivals, in part because it symbolizes luck, auspiciousness, health, and long life.

\section{Chinese Adolescent Alcohol Use}

There are few studies of Chinese adolescent alcohol use. A review of the available literature" suggests the following:

- Drinking begins between 12 and 15 years of age.

- The proportion of adolescents who are drinkers in Shanghai and Beijing is similar to the proportion of American adolescents who are drinkers, but the rate of frequent drinking is lower among Chinese adolescents than among US adolescents.

- Adolescent alcohol use in China varies by region. Adolescent alcohol use in more isolated areas is lower than in the large urban areas, at least for beer.

- Male and female patterns of alcohol use differ significantly, with male use greatly exceeding female use.

- Parental and peer alcohol use influences young people's alcohol use.

- Beer is the most popular alcoholic beverage among adolescents.

- Traditional and cultural values shape alcohol use by, for example, discouraging drinking among children and females and by limiting alcohol use to certain times and events. A strong tradition of maintaining reputation of one's self, one's family, and one's work unit stipulates that drinkers control themselves and refrain from bad behavior after drinking.

- There are times and places, especially in the business community, when extreme drinking is accepted and even expected.

\section{Alcohol Expectancy Theory}

Expectancy theory ${ }^{15-18}$ has served as a conceptual basis for studying adolescent alcohol use for the past 20 years in the United States. Expectancy theory is a memory-based cognitive learning theory. An expectancy is the repeated perception of an association between a behavior and an outcome, which leads to the memorization of the association. The memory is in the form of an "if-then" relationship between the behavior and its consequences. Examples of alcohol expectancy statements are the following: If I drink alcohol, then I will feel relaxed; if I drink alcohol then I will be seen as strong; and if I drink alcohol then it will be easier to join in the conversation. Once memorized, the associations then go on to influence future behaviors. In this manner, early learning experiences influence later behavior by means of the learned expectancy associated with drinking. ${ }^{15}$

Expectancies incorporate many influences, including parental modeling, personality characteristics, biological vulnerability to alcohol, peer influences, sociocultural influences, mass media, and cultural influences. Alcohol expectancies are learned and can be formed at an early age, even before the actual consumption of alcohol, based on observations of other people's alcohol use and their reactions. Expectancies can be revised on the basis of one's own experiences with alcohol use. Expectancies have been found to be useful in predicting drinking behavior, patterns of use, the onset of use, and patterns of problematic use. ${ }^{15-}$ ${ }_{18}$ Longitudinal studies have shown that expectancies are antecedent predictors of drinking behavior. ${ }^{17}$ There is little information on the influence of expectancies on Chinese adolescents' drinking behavior. 


\section{The Objective of This Study}

The purpose of this study was to examine whether there were differences in Chinese high school students' expectancies by drinking status (nondrinker, occasional drinker, regular drinker) and whether male and female students differed in their expectancies.

\section{Method}

The methodology used was a questionnaire survey of high school students in 2 cities in Inner Mongolia, China.

\section{Participants}

Participants were a convenience sample of 1285 high school students from schools in Tongliao City and Hohhot City in Inner Mongolia, China. Complete data were obtained from 1244 students $(M=627, F=617 ; 664$ in the 10th grade, 517 in the 11th grade, and 63 in the 12th grade). The majority of students (763) were of Han ethnicity, with 423 students of Mongolian ethnicity. The remaining 58 students were of other or unknown ethnicity.

\section{Measures}

The Chinese Adolescent Alcohol Expectancy Scale (CAEQ). The scale, called the Chinese Adolescent Expectancy Questionnaire, was initially developed from 3 months of fieldwork involving in-depth interviews with individual students and focus group discussions exploring alcohol expectancies with 64 adolescents in Inner Mongolia. Also contributing to the process was a review of previous alcohol expectancy scales and a review of available literature. From this work, a 131-item CAEQ was developed and pretested with 120 students. Wording and question structure were changed in a few questions based on the pretest. The revised scale contained 131 items and assessed expectancy statements with a 6-point Likert scale from 1 (strongly disagree) to 6 (strongly agree).

The 131-item CAEQ was administered to 919 students from Inner Mongolia. Principal components analysis was used to identify the dimensionality of questionnaire items. This analysis resulted in an 8-factor solution. ${ }^{19,} 20$ The 131-item CAEQ was again factored using principle components with varimax rotation. This analysis confirmed the 8 -factor structure of the scale identified previously with the principle components analysis. The items in each of the factors were then examined for statistical adequacy (loadings above 0.30, loading uniquely on a single factor) and conceptual consistency with other items in the factor. Based on these criteria, we removed poorly fitting items.

The final CAEQ instrument contained 88 items. The scales with sample items and their coefficient $\alpha$ reliability estimates are shown in Table 1 . Expectancy scores were computed as the mean score of the items in each of the 8 CAEQ factors. $\alpha$ values for most scales were satisfactory, although the values for harm to person/reputation, negative uses of alcohol, and beneficial drinking/moderation scales were somewhat low. The $\alpha$ values for the CAEQ are within the same ranges as the test-retest reliabilities reported for the Alcohol Expectancy Questionnaire (AEQ) developed in the United States for both the adult and adolescent versions. ${ }^{16}$

Drinking measures. We created drinking status categories as Follows: Nondrinkers were those who reported never drinking or not drinking within the past year, occasional drinkers were those who drank in the last year but not in the last 30 days, and regular drinkers were those who drank both in the last year and within the last 30 days. A valid measure of drinking quantity could not be obtained because of the lack of standardized drinking containers, unregulated alcohol content, varying concentration of alcohol in different drinks, 
Table 1. Chinese Adolescent Alcohol Expectancy Questionnaire Factors and $\alpha$ Values

\begin{tabular}{|c|c|c|}
\hline Factor & $\alpha$ & Sample Items \\
\hline $\begin{array}{l}\text { General negative } \\
\text { consequences, } \\
18 \text { items }\end{array}$ & .76 & $\begin{array}{l}\text { Drinking alcohol causes dizziness or headache. } \\
\text { Drinking alcohol tends to get me in trouble. } \\
\text { Drinking alcohol is harmful to health. } \\
\text { Drinking causes delay of work or business. }\end{array}$ \\
\hline $\begin{array}{l}\text { Harm to person/ } \\
\text { reputation, } 8 \text { items }\end{array}$ & .56 & $\begin{array}{l}\text { Females drinking can influence her reputation. } \\
\text { Drinking alcohol will influence one's social development. } \\
\text { Students with good academic records drink less frequently. }\end{array}$ \\
\hline $\begin{array}{l}\text { Negative uses of } \\
\text { alcohol, } 7 \text { items }\end{array}$ & .50 & $\begin{array}{l}\text { People may act excessively on opposite sex by using alcohol as an excuse. } \\
\text { I may drink alcohol when I am feeling bad. } \\
\text { The purpose of drinking is to show off oneself before other people. }\end{array}$ \\
\hline $\begin{array}{l}\text { General positive } \\
\text { perceptions, } 14 \text { items }\end{array}$ & .72 & $\begin{array}{l}\text { Drinking is welcome behavior. } \\
\text { Drinking should he filled with joy. } \\
\text { A person drinking a large amount of alcohol is admired. } \\
\text { Drinking is worth its cost. }\end{array}$ \\
\hline $\begin{array}{l}\text { Tension reduction/ } \\
\text { relaxation, } 16 \text { items }\end{array}$ & .72 & $\begin{array}{l}\text { Drinking can relieve mental pressure. } \\
\text { Drinking alcohol makes people relax. } \\
\text { Drinking makes people forget displeased things. } \\
\text { Drinking makes fun. }\end{array}$ \\
\hline $\begin{array}{l}\text { Drinking as social } \\
\text { courtesy, } 9 \text { items }\end{array}$ & .63 & $\begin{array}{l}\text { I am afraid to hurt others' feeling when I refuse their toast. } \\
\text { People would be disappointed without alcohol at parties. } \\
\text { Toasting shows respect. }\end{array}$ \\
\hline $\begin{array}{l}\text { Social facilitation, } \\
7 \text { items }\end{array}$ & .61 & $\begin{array}{l}\text { It is easier to handle affairs when drinking. } \\
\text { Drinking can boost one's courage. } \\
\text { Drinking helps improve interpersonal relationship. }\end{array}$ \\
\hline $\begin{array}{l}\text { Beneficial drinking/ } \\
\text { moderation, } 9 \text { items }\end{array}$ & .59 & $\begin{array}{l}\text { Drinking but not drunkenness is delighted. } \\
\text { Drinking a little is acceptable. } \\
\text { A little drinking is beneficial for health. }\end{array}$ \\
\hline
\end{tabular}

the sale of alcohol in bottles of different sizes, and the practice of consuming alcohol from glasses, cups, and bowls of different sizes; consequently only frequency was used to categorize drinkers and nondrinkers.

\section{Procedures}

Students completed the CAEQ and answered demographic and alcohol use questions in their classroom. The staff of Inner Mongolia Autonomous Region Health Education Institute and local health workers administered the questionnaire. The teachers were not present in the classrooms during the survey. The questionnaire took approximately 30 to 50 minutes to complete. Although students were informed that participation was voluntary, participation was $100 \%$ in all classrooms.

\section{Analysis}

Multivariate analysis of variance (MANOVA) was used to examine whether expectancies differed for drinking status (nondrinker, occasional drinker, regular drinker) and gender. A significance level of $\alpha=.01$ was used for all tests.

\section{Results}

Significant main effects were found for drinking status (Wilks's $\lambda=0.928, F(16,2462)$ $\left.=5.83, P<.001, \eta^{2}=0.036\right)$ and gender (Wilks's $\lambda=0.975, F(8,1231)=4.02, P<.001, \eta^{2}=$ 
Table 2. Students' Mean Scores on Alcohol Expectancies by Drinking Status ${ }^{a}$

\begin{tabular}{|c|c|c|c|c|c|c|c|c|}
\hline & \multicolumn{2}{|c|}{ Nondrinker } & \multicolumn{2}{|c|}{$\begin{array}{c}\text { Occasional } \\
\text { Drinker }\end{array}$} & \multicolumn{2}{|c|}{$\begin{array}{l}\text { Regular } \\
\text { Drinker }\end{array}$} & \multirow[b]{2}{*}{$F$} & \multirow[b]{2}{*}{$\eta^{2}$} \\
\hline & $\bar{M}$ & $\overline{\mathrm{SD}}$ & $\mathrm{M}$ & $\mathrm{SD}$ & M & $\mathrm{SD}$ & & \\
\hline General negative consequences & $4.28_{\mathrm{b}}$ & 0.65 & $4.29 \mathrm{~b}$ & 0.70 & $4.07_{c}$ & 0.63 & $8.72^{\mathrm{d}}$ & 0.014 \\
\hline Harm to person/reputation & $3.72_{\mathrm{b}}^{\mathrm{b}}$ & 0.73 & $3.47_{c}^{\mathrm{b}}$ & 0.70 & $3.48^{c}$ & 0.75 & $11.26^{\mathrm{d}}$ & 0.018 \\
\hline Negative uses of alcohol & $3.10^{\mathrm{b}}$ & 0.79 & $3.00^{c}$ & 0.70 & $3.17^{\mathrm{c}}$ & 0.80 & 2.04 & 0.003 \\
\hline General positive perceptions & $2.81_{b}$ & 0.67 & $2.90_{b}$ & 0.69 & $3.17_{c}$ & 0.70 & $14.60^{\mathrm{d}}$ & 0.023 \\
\hline Tension reduction/relaxation & $3.15^{\circ}$ & 0.61 & $3.16^{\circ}$ & 0.59 & $3.27^{c}$ & 0.68 & 2.84 & 0.005 \\
\hline Drinking as social courtesy & 3.38 & 0.71 & 3.57 & 0.76 & 3.48 & 0.76 & 3.77 & 0.006 \\
\hline Social facilitation & 3.44 & 0.80 & 3.48 & 0.77 & 3.59 & 0.85 & 1.46 & 0.002 \\
\hline Beneficial drinking/moderation & $3.49_{b}$ & 0.72 & $3.77_{c}$ & 0.68 & 3.64 & 0.75 & $8.73^{\mathrm{d}}$ & 0.014 \\
\hline
\end{tabular}

a. Nondrinker, $n=891$; occasional drinker, $n=132$; regular drinker, $n=221$.

Means with different subscripts differ significantly in pairwise comparisons using Bonferroni adjustment. Cohen's $d$ for pairwise comparisons: 1) general negative consequences, regular drinker to occasional drinker $=-$ 0.33 , regular drinker to nondrinker $=-0.32 ; 2$ ) harm to person/reputation, regular drinker to nondrinker $=-$ .32 , occasional drinker to nondrinker $=-0.34 ; 3$ ) general positive perceptions, regular drinker to occasional drinker $=0.39$, regular drinker to nondrinker $=0.52 ; 4)$ beneficial drinking $/$ moderation, occasional drinker to nondrinker $=0.38$.

d. $P<.001$

0.025). The interaction effect was not significant (Wilks's $\lambda=0.977, F(16,2462)=1.79, P=$ $\left..028, \eta^{2}=0.011\right)$.

Mean scores and MANOVA results for the comparisons based on drinking status are shown in Table 2. Regular drinkers had lower negative consequences and higher positive perception expectancies than nondrinkers or occasional drinkers and lower harm to person/reputation expectancies than nondrinkers. Occasional drinkers had higher beneficial/moderation expectancies than nondrinkers. The effect sizes for all significant differences were approximately one third of a standard deviation, indicating a moderate and meaningful difference.

Mean scores and MANOVA results for the gender comparisons are shown in Table 3. Boys and girls differed only in general positive perceptions. Boys had higher positive perception expectancies than girls. The effect size for general positive perceptions was approximately one third of a standard deviation, indicating a moderate and likely meaningful difference. There were no other significant differences, although boys generally tended to rate positive expectancies higher and negative expectancies lower than girls.

\section{Discussion}

\section{Relationship of Alcohol Use and Alcohol Expectancies}

Regular drinkers had higher general positive perceptions and lower general negative consequences expectancy perceptions than either occasional drinkers or nondrinkers. This suggests that expectancies may play an important role in the frequency of drinking by Chinese adolescents. Results also suggest that those who drink regularly may react more to global expectations for more positive outcomes and fewer negative outcomes in general than to expectations about more specific physical or social outcomes.

Nondrinkers had higher harm to person/reputation expectancies than either occasional or regular drinkers. This suggests that the expectation that drinking could damage one's reputation or cause one to be looked on unfavorably by others may play an important role in these adolescents' decision making concerning abstinence. Occasional drinkers had higher 
Table 3. Students' Mean Scores on Alcohol Expectancies by Gender

\begin{tabular}{|c|c|c|c|c|c|c|}
\hline & \multicolumn{2}{|c|}{ Male } & \multicolumn{2}{|c|}{ Female } & \multirow[b]{2}{*}{$F$} & \multirow[b]{2}{*}{$d^{\mathrm{a}}$} \\
\hline & M & SD & M & SD & & \\
\hline General negative consequences & 4.17 & 0.67 & 4.31 & 0.63 & 4.99 & -0.21 \\
\hline Harm to person/reputation & 3.59 & 0.75 & 3.72 & 0.73 & 3.19 & -0.18 \\
\hline Negative uses of alcohol & 3.10 & 0.77 & 3.10 & 0.80 & 0.15 & 0.00 \\
\hline General positive perceptions & 2.99 & 0.69 & 2.77 & 0.67 & $19.60^{\mathrm{b}}$ & 0.32 \\
\hline Tension reduction/relaxation & 3.16 & 0.63 & 3.19 & 0.61 & 0.04 & -0.05 \\
\hline Drinking as social courtesy & 3.45 & 0.74 & 3.39 & 0.72 & 0.34 & 0.08 \\
\hline Social facilitation & 3.54 & 0.82 & 3.40 & 0.78 & 4.81 & 0.17 \\
\hline Beneficial drinking/moderation & 3.56 & 0.75 & 3.53 & 0.70 & 0.47 & 0.04 \\
\hline
\end{tabular}

a. $d=$ Effect size computed by Cohen's $d$; boys, $n=627$; girls, $n=617$.

b. $P<.001$

beneficial drinking/moderation expectancies than nondrinkers. This suggests that drinking for occasional drinkers may be the result of expected benefits from pursuing a moderate course of drinking, which operates as a protective factor against more frequent drinking.

\section{Relationship of Gender and Alcohol Expectancies}

Boys had higher general positive perception expectancies than girls, suggesting that they are more likely to see drinking as something that results in positive outcomes. There were no other significant differences, although boys generally tended to rate positive expectancies higher and negative expectancies lower than girls. These results are consistent with other studies in the West ${ }^{17,18}$ that have found few differences in expectancies between boys and girls.

\section{Unique Nature of Chinese Students' Alcohol Expectancies}

Five of the scales identified in the CAEQ were similar to those found in expectancy research in the United States ${ }^{16-18}$ (General Negative Consequences, Harm to Person/Reputation, Negative Uses of Alcohol, General Positive Perceptions, Tension Reduction/Relaxation). Three of the scales appeared to reflect unique aspects of Chinese culture (Drinking as Social Courtesy, Social Facilitation, Beneficial Drinking/Moderation)

This suggests that in addition to somewhat universal cross-cultural alcohol expectancies, adolescents may develop expectancies that reflect the particular culture and experiences to which they are exposed. These findings are consistent with alcohol expectancy theory, which proposes that expectancies are shaped by experience, and experience is shaped by culture.

\section{Conclusion/Recommendation}

Knowing about the alcohol expectancies of different groups provides valuable insight for educators and policymakers who are interested in moderating the negative effects and protecting the important social roles that alcohol plays in some societies. Expectancies are learned; therefore, expectancies that are directly linked to high-risk behaviors, for example, the possible expectancy that alcohol enhances sexuality can become the focus of carefully designed educational programs that challenge the expectancy. Similarly, if expectan- 
cies suggest high-risk traffic safety behavior, they may become the focus of debates related to public policy. Expectancies that are associated with low-risk behaviors can be strengthened in educational and community settings and be the focus of educational programs for younger children and parents. Knowing more about expectancies, particularly, in societies that are undergoing cultural changes or experiencing an influx of Western influences that could weaken traditional protective cultural influences could provide a useful gauge to assess the extent and rate of these changes.

This study suggests a caution in generalizing findings about the structure of expectancies across cultures and nationalities and a need to consider local customs, beliefs, and practices when assessing the expectancies persons may have about alcohol. Clearly, further research into culturally specific expectancy patterns in China and other countries is needed to extend these findings.

This study is limited by the sampling of students from only one region of China. Future research needs to extend the examination of expectancies to a broader, more representative sample of Chinese adolescents. Also, the study is cross-sectional. Future research needs to look at the development of expectancies longitudinally across the high-school years and at how this is related to longitudinal change in drinking. Research also needs to examine the relationships between expectancies and problem behaviors associated with drinking, such as drinking and driving. It would also he desirable to examine the relations between expectancies and drinking quantity as well as frequency, although developing sound measures of quantity remains a significant methodological problem. ${ }^{14}$ Continued development of the CAEQ is also needed to enhance reliability and validity. Despite these limitations, the study provides the first data on adolescents' alcohol expectancies in China and a solid starting point for continued research.

\section{References}

1. World Health Organization. Global Status Report on Alcohol. Geneva, Switzerland: World Health Organization; 1999. Document \#WHO/HSC/SAB/99-11.

2. World Advertising Research Center. China rises to the top of the glass. http://www.warc.com/ News/TopNews.asp?ID=20138 Published August 28, 2006. Accessed April 29, 2008.

3. World Advertising Research Centre, Commission for Distilled Spirits (Netherlands). World Drink Trends 2005 Edition. Henley-on-Thames. Oxfordshire, UK: Produktschap voor Gedistilleerde Dranken in association with NTC, 2005.

4. http://asia-interprise-vinitech-china.com Wine Production in China. http://www.wines-info. com/html/192/5208.html Published August 6, 2005. Accessed April 29, 2008.

5. World Health Organization. Global status report on alcohol 2004: Part I. Global overviews. http://www.who.int/substance_abuse/publications/globalstatusreportalcohol2004_alcconsumpt.pdf Published 2004. Updated 2005. Accessed April 29, 2008.

6. Qian L, Newman IM, Wu YW, Maas MR, Hou P. Alcohol in China: Production, Consumption and Related Social Problems. University of Nebraska, NE: National Institute of Health Education/ China CDC and Nebraska Prevention Center for Alcohol and Drug Abuse, 2007.

7. Zhang JF, Casswell S, Cai HM. Increased drinking in a metropolitan city in China: a study of alcohol consumption patterns and changes. Addiction. 2008; 103:416-423.

8. Helongjiang Business College and Beijing Food Production Cooperation. Chinese Alcohol [in Chinese]. Beijing, PRC: China Financial and Economy Press, 1980.

9. Deng YL, He W. Addictive behavior. In: Yang D, ed. Behavioral Medicine. Hunan, PRC: Hunan Normal University Press, 1990:64-71. 
10. Lee JA. Chinese, alcohol and flushing: Social-historical and bio-behavioral considerations. J Psychoactive Drugs. 1987; 19:319-327.

11. The Cambridge Encyclopedia of China. London, UK: Cambridge University Press, 1982.

12. Shen Y, Wang Z. China. In: Grant M, ed. Alcohol and Emerging Markets: Patterns, Problems and Responses. Philadelphia, PA: Brunner/Mazel, 1998:123-144.

13. Singer K. Drinking patterns and alcoholism in the Chinese. Br J Addict. 1972; 67:3-14.

14. Newman IM, Qian L, Xue JP. Da xue sheng yin jiu diao cha: diao cha wen ti gui fan de bi yao xing [College student alcohol surveys: the need for uniform questions]. Zhongguo Yaowu Lanyong Fangzhi Zazhi [Chin J Drug Abuse Prev Treat.] 2004; 10:272-275.

15. Smith GT, Goldman MS. Alcohol expectancy theory and the identification of high-risk adolescents. In: Boyd GM, Howard J, Zucker RA, eds. Alcohol Problem Among Adolescents: Current Directions in Prevention Research. Hillsdale, NJ: Lawrence Erlbaum, 1995; 236-104.

16. Brown SA, Christiansen BA, Goldman MS. The Alcohol Expectancy Questionnaire: An instrument for the assessment of adolescent and adult alcohol expectancies. J Stud Alcohol. 1987; 48:483-491.

17. Kline RB. Eight-month predictive validity and covariance structure of the Alcohol Expectancy Questionnaire for Adolescents (AEQ-A) for junior high school students. J Stud Alcohol. 1996; 57:396-405.

18. George WH, Frone MR, Cooper ML, Russell M, Skinner JB, Windle M. A revised Alcohol Expectancy Questionnaire: Factor structure confirmation and invariance in a general population sample. J Stud Alcohol. 1995; 56:177-185.

19. Newman IM, Qu M, Shell DF, Li YC, Gao FF. Alcohol expectancies among adolescents in Inner Mongolia. In: Jones AK, Lundquist BV, eds. Challenges for Public Health at the Dawn of the 21st Century: Selected Proceedings from the Ninth International Congress World Federation of Public Health Associations, 2-6 September 2000, Beijing, China. Washington, DC: World Federation of Public Health Associations, American Public Health Association, 2001: 111-113.

20. Qu M, Newman IM, Shell DF, Li YC, Gao FF. Relationship of grade, sex, and alcohol use to alcohol expectancies among Chinese adolescents. Paper presented at 128th Annual Meeting of the American Public Health Association; November 12-16, 2000, Boston, MA. 